\title{
A New Rapid and Sensitive Spectrophotometric Method for Determination of a Biopolymer Chitosan
}

\author{
Mohamed E. I. Badawy \\ Department of Pesticide Chemistry and Technology, Faculty of Agriculture, Alexandria University El-Shatby, Alexandria 21545, Egypt \\ Correspondence should be addressed to Mohamed E. I. Badawy, m_eltaher@yahoo.com \\ Received 10 May 2012; Accepted 5 June 2012 \\ Academic Editor: R. J. Linhardt \\ Copyright ( $) 2012$ Mohamed E. I. Badawy. This is an open access article distributed under the Creative Commons Attribution \\ License, which permits unrestricted use, distribution, and reproduction in any medium, provided the original work is properly \\ cited. \\ A novel approach of spectrophotometric quantification of chitosan based on one-step depolymerization with sodium nitrite \\ followed by reaction of the end product with thiobarbituric acid has been proposed, optimized, and validated. In this process, \\ chitosan is converted into 2,5-anhydro-D-mannose that reacts with thiobarbituric acid to form pink color. The color that resulted \\ from the reaction was stabilized and measured at $555 \mathrm{~nm}$. The method optimization was essential as many procedural parameters \\ influenced the accuracy of the determination including hydrolysis conditions, thiobarbituric acid concentration, reaction time, \\ $\mathrm{pH}$, reaction temperature, and color stability period. Under given optimized conditions that appeared to be critical, chitosan was \\ quantitatively analyzed and the calibration graph was linear over the range of $10-50 \mu \mathrm{g} / \mathrm{mL}\left(r^{2}=0.999\right)$. This approach was \\ applied for determination of chitosan in pharmaceutical formulation (chitocal) and had a recovery rate of higher than $96 \%$. The \\ developed method is easy to use and highly accurate.
}

\section{Introduction}

Recently, much attention has been paid to chitosan as a potential polysaccharide resource. Chitosan is a linear amino polysaccharide of glucosamine and $N$-acetylglucosamine units and is obtained by alkaline deacetylation of chitin [1]. The following major characteristics of chitosan make this polymer advantageous for numerous applications: (1) it has a defined chemical structure; (2) it can be chemically and enzymatically modified; (3) it is physically and biologically functional; (4) it is biodegradable and biocompatible with many organs, tissues, and cells; (5) it can be processed into several products including flakes, fine powders, beads, membranes, sponges, cottons, fibers, and gels. Therefore, chitosan becomes of great interest as a new functional material of high potential in various fields and the discovery or development of methods for chitosan determination is imperative [2-5].

Although research activities dealing with chitosan are numerous, a generally accepted simple method for direct quantitative analysis is lacking. Chitosan can be degraded to glucosamine monomer by hydrolysis, and there are several reports on the determination of glucosamine by chromatographic, colorimetric, and fluorimetric techniques, or a combination of these [6-8]. Eikenes et al. [6] developed a method for determination of chitosan in wood and water samples based on acidic hydrolysis of chitosan to glucosamine followed by online derivatization by $o$-phthalaldehyde, chromatographic separation, and fluorescent detection. Roseman and Daffner [9] determined the concentration of glucosamine by acetylating followed by photometric detection of $N$-acetyl glucosamine.

A novel approach of colorimetric quantification of chitosan based on the derivatization reaction of amino groups in chitosan with $o$-phthalaldehyde and a thiol- $N$-acetyl-Lcysteine has been developed by Larionova co-workers [10]. The procedure conditions have been optimized for chitosan assay in the presence of polyanionic electrolyte dextran sulphate. The method has proven to be convenient and reliable for quantitative determination of either the concentrations of chitosan of various molecular weights or their degree of deacetylation. 
Based on the fact that, in dilute solutions, the amino group is at its most accessible form for optimum quantification, several spectrophotometric approaches have been reported. The determination of aminoglucose by the indole reaction [11] and the formation of a complex of chitosan with ninhydrin are the most used protocols $[12,13]$. These methods did not involve any pretreatment (i.e., hydrolysis) of the solution, but the method was highly dependent on the degree of deacetylation of chitosan. More reliable analytical methods are colorimetric assay of chitosan with various anionic dyes, for instance, C.I. Acid Orange 7, C.I. Acid Red 13, C.I. Acid Red 27, Orange II, Alizarin S, Alizarin GG, Congo Red [14], Cibacron Brilliant Red 3B-A [15, 16]. However, these techniques based on the reactions between free amino groups of chitosan and acting agents are ineligible for determination of chitosan in presence of substances bearing primary amino groups, including peptides [17]. Recently, an electrochemical method based on the oxidationreduction peaks produced by chitosan solubilisation in an acidic buffer has been reported as a sensitive measurement for this polymer [18]. However, the application of this analysis to complex mixtures would be difficult.

Most quantitative analysis of polysaccharides such as chitosan entails total hydrolysis to monosaccharides followed by subsequent characterization of the monomers $[6,19,20]$. However, the glycosidic linkages of chitosan are resistant to acid hydrolysis such as the anthrone or phenol-sulphuric acid methods [21]. In addition, such hydrolysis methods are difficult to apply. Chitosanases may be used for depolymerization of chitosan, but availability and costs limit the use of such enzymes [22].

In the present work, a selective and sensitive method for determination of chitosan was developed using sodium nitrite hydrolysis and online derivatization with thiobarbituric acid in basic medium to form pink color. Sodium nitrite causes depolymerization and deamination of chitosan and converts it to 2,5-anhydro-D-mannose $[19,20]$. The procedure conditions have been optimized and evaluated for chitosan assay in chitocal as a pharmaceutical formulation.

\section{Materials and Methods}

2.1. Principle of the New Assay. The method is based on determination of chitosan after deaminative cleavage by sodium nitrite $\left(\mathrm{NaNO}_{2}\right)$ and coupling of the 2,5-anhydro$\mathrm{D}$-mannose thus produced with thiobarbituric acid to give pink product. 2,5-Anhydro-D-mannose represents the sum of glucosamine (GlcN) and $N$-acetyl glucosamine (GlcNAc). Depolymerization of chitosan by using of $\mathrm{NaNO}_{2}$ is selective, rapid, easily controlled, no side reactions have been observed with chitosan, and, as a consequence, the stoichiometry and reaction products are well established [23, 24]. Furthermore, because chitosan is soluble in dilute acids, the reaction with $\mathrm{NaNO}_{2}$ is homogeneous. The depolymerization mechanism involves a deamination of $(1 \rightarrow 4)$-linked 2-acetamido2 -deoxy- $\beta$-D-glucopyranose unit forming 2,5 -anhydro-Dmannose at the new reducing end as shown in Figure 1(a) [24-27]. The end product contains an aldehyde which is determined colorimetrically with thiobarbituric acid.
Thiobarbituric acid undergoes a Knoevenagel condensation reaction with aldehydes to give the color-condensed product according to Tietze and Beifuss [28] (Figure 1(b)). The observed level of pink product was related to the chitosan present in the sample.

2.2. Assay Reagents. All experiments were performed with analytical reagent grade chemicals. Low molecular weight of acid-soluble chitosan (made from coarse ground crab with $89 \%$ degree of deacetylation) was purchased from SigmaAldrich Co. (USA). Chitosan stock solution was made by dissolving $100 \mathrm{mg}$ of chitosan in $100 \mathrm{~mL}$ of $1 \%(\mathrm{v} / \mathrm{v})$ aqueous acetic acid; the chitosan dissolves readily on shaking. From this solution, suitable dilutions can be made when required. An aqueous solution of $0.5 \mathrm{M} \mathrm{NaNO}_{2}$ was prepared, and the solution should be kept between 0 and $4^{\circ} \mathrm{C}$. 2-Thiobarbituric acid standard solution $(0.04 \mathrm{M})$ was prepared by dissolving $0.576 \mathrm{~g}$ of reagent $(\geq 98 \%$, Sigma-Aldrich Co., USA) in $100 \mathrm{~mL}$ of distilled water with warming for $15 \mathrm{~min}$.

\subsection{Procedure. Chitosan solution was pipetted into the test} tube, and the $\mathrm{NaNO}_{2}$ reagent was added from a micropipette $(0.1 \mathrm{~mL}$ of $0.5 \mathrm{M})$. The mixture was shaken briefly. The tubes were kept at $80^{\circ} \mathrm{C}$ for $30 \mathrm{~min}$ in a water bath to complete the depolymerization-deamination reaction. After depolymerization, the $\mathrm{pH}$ was raised to 8 by adding $0.2 \mathrm{~mL} \mathrm{NaOH}$ $(0.1 \mathrm{M})$ and the solution was then shaken, and $0.5 \mathrm{~mL}$ of the thiobarbituric acid solution $(0.04 \mathrm{M})$ was finally added. The tubes were incubated a second time at $80^{\circ} \mathrm{C}$ for $10 \mathrm{~min}$ in a water bath. The solution was briefly cooled, and the absorbance was measured at $555 \mathrm{~nm}$ by Spectrophotometer (Unico 1200-Spectrophotometer, USA) against blank.

2.4. Assay of Chitosan in Pharmaceuitical Formulation. In Chitocal capsules $(500 \mathrm{mg}+100 \mathrm{mg}$ ascorbic acid $+80 \mathrm{mg}$ gymnema sylvestre, manufactured by Aldebeiky Group-DBK Pharma, Cairo, Egypt), the well-mixed powdered content of 10 capsules was used in the assay. A weight of $100 \mathrm{mg}$ of the powder was transferred into volumetric flask and dissolved in $50 \mathrm{~mL}$ aqueous acetic acid solution $(1 \%, \mathrm{v} / \mathrm{v})$ then adjusted to volume. Different aliquots $(20,40,60,80$, and $100 \mu \mathrm{L}$ ) of this solution were analyzed according to the proposed procedure as previously mentioned. For the recovery study, the standard addition method has been used. Different amounts of the corresponding pure chitosan were added to a fixed amount of dosage form (capsule) where chitosan had been determined. Results are the average of triplicate readings of all determinations in the solutions.

2.5. Statistical Methods. Linear regression analysis of the absorbance at $555 \mathrm{~nm}$ versus chitosan concentration, determination of confidence intervals, and other statistical tests were carried out with SPSS 12.0 software program (Statistical Package for Social Sciences, USA).

\section{Results and Discussion}

3.1. Spectral Analysis. Firstly, we checked the use of acetic acid to dissolve chitosan because this is the usual solvent for 


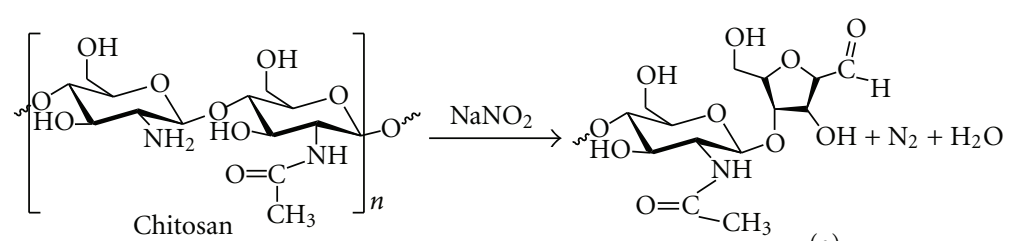

(a)
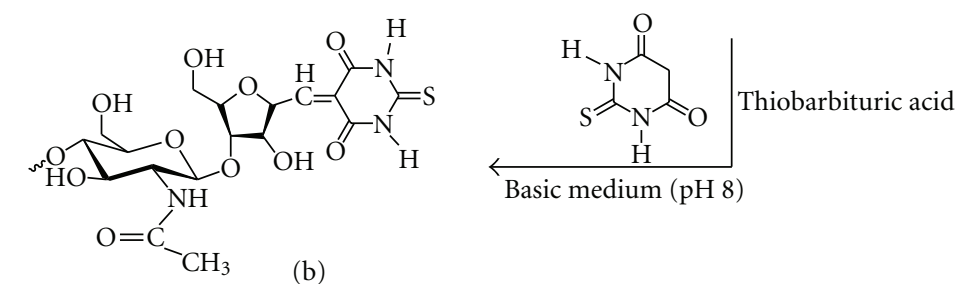

Product of pink fluoresent color

FIGURE 1: The mechanism by which the nitrous acid reaction leads to chain cleavage resulting in a 2,5-anhydro-D-mannose-reducing end (a) and proposed reaction of the reducing end in basic medium with thiobarbituric acid to generate a pink fluorescent dye (b).

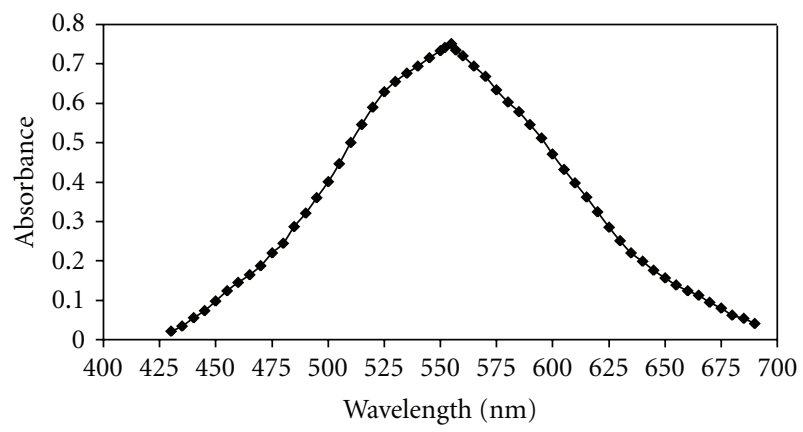

FIGURE 2: Absorbance spectrum of the pink-fluorescent product from the reaction between reducing end of chitosan and thiobarbituric acid. 400 to $700 \mathrm{~nm}$ spectrum is plotted and clearly shows the maximum wavelength is $555 \mathrm{~nm}$ for the pink color formed.

chitosan solubility. Absorption scans in the range of 400 to $700 \mathrm{~nm}$ were performed on $25 \mu \mathrm{g} / \mathrm{mL}$ chitosan solution in $1 \%(\mathrm{v} / \mathrm{v})$ aqueous acetic acid solution. The same solution without chitosan was used as blank. The color developed within seconds of the mixing of thiobarbituric acid solution with the reagents and reached stability after $10 \mathrm{~min}$. The spectral absorbance of this color is shown in Figure 2. The product reacts with thiobarbituric acid giving rise to a pink-colored derivative with excitation maximum located at $555 \mathrm{~nm}$. Therefore, all absorbance measurements were performed at this wavelength. To obtain high sensitivity, it is necessary to investigate the effect of all parameters that could influence the chemical reactions and the performance of the colored complex.

3.2. Optimization of the Reaction Conditions. For survey of the optimal reaction conditions, seven factors were considered including the sample size, the amount of $\mathrm{NaNO}_{2}$, the $\mathrm{pH}$, the temperature, the depolymerization time, the amount of the thiobarbituric acid reagent, and the stability of the color formed. Three chitosan concentrations $(10,25$ and $50 \mu \mathrm{g} / \mathrm{mL}$ ) were selected to allow study the effect of these

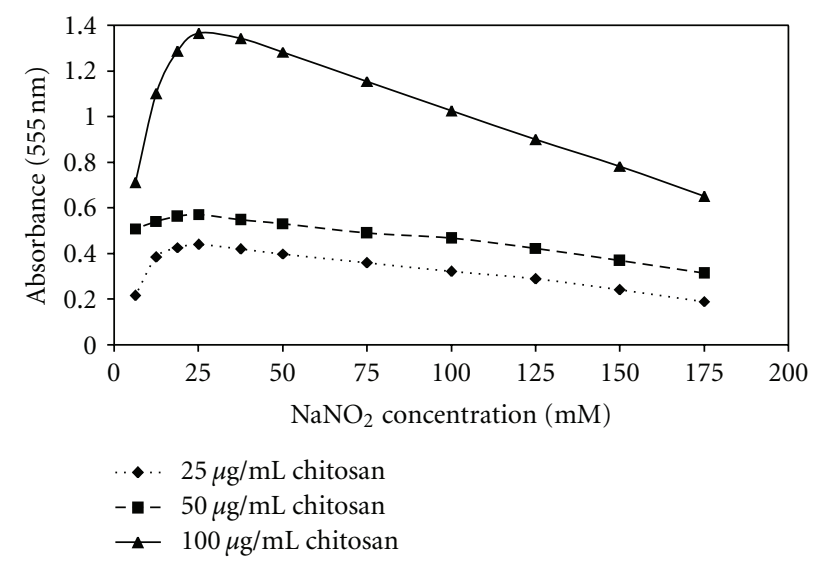

FIGURE 3: Effect of sodium nitrite concentration that used as a depolymerized reagent of chitosan for $30 \mathrm{~min}$ on the rate and intensity of the color development.

factors. Therefore, the sequence was adopted as follows: chitosan, $\mathrm{NaNO}_{2}, \mathrm{pH}$ increase to 8, thiobarbituric acid, and then the absorbance measured. Using this sequence, when the $25 \mathrm{mM} \mathrm{NaNO}$ was added to chitosan solution, incubation at $80^{\circ} \mathrm{C}$ for $30 \mathrm{~min}$, and $10.8 \mathrm{mM}$ thiobarbituric acid as added immediately after the $\mathrm{pH}$ adjusted to 8 , the maximal absorbance was obtained.

3.2.1. Effect of the Sodium Nitrite Concentration. The effect of $\mathrm{NaNO}_{2}$ concentration was investigated within the range of 6.25 to $175 \mathrm{mM}$. The results revealed that the absorbance increased by increasing the reagent concentration up to $25 \mathrm{mM}$ and decreased at higher concentrations (Figure 3). Therefore, $25 \mathrm{mM} \mathrm{NaNO}$ was the optimum concentration and was applied in the proposed method. It could be deduced from the curves that $25 \mathrm{ug} / \mathrm{mL}$ chitosan was more sensitive to $\mathrm{NaNO}_{2}$ degradation compared with that of 50 and $100 \mathrm{ug} / \mathrm{mL}$ chitosan. It seems that the depolymerization of chitosan was influenced not only by the concentration of 


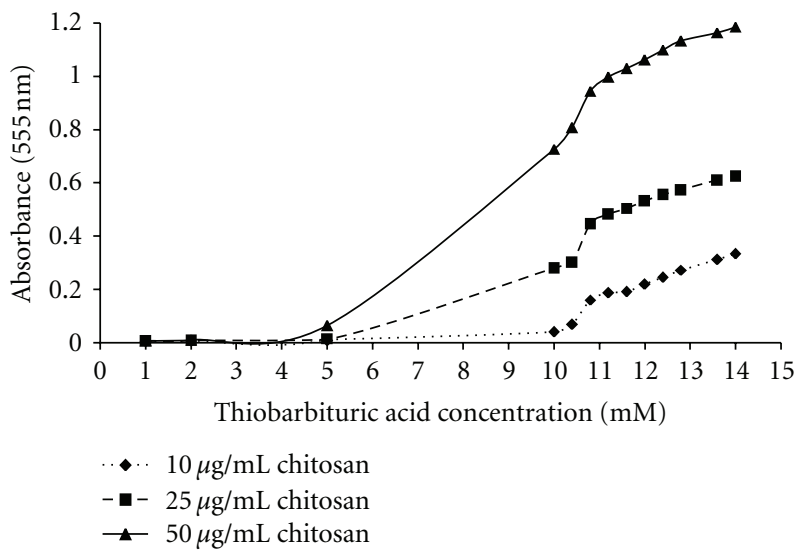

(a)

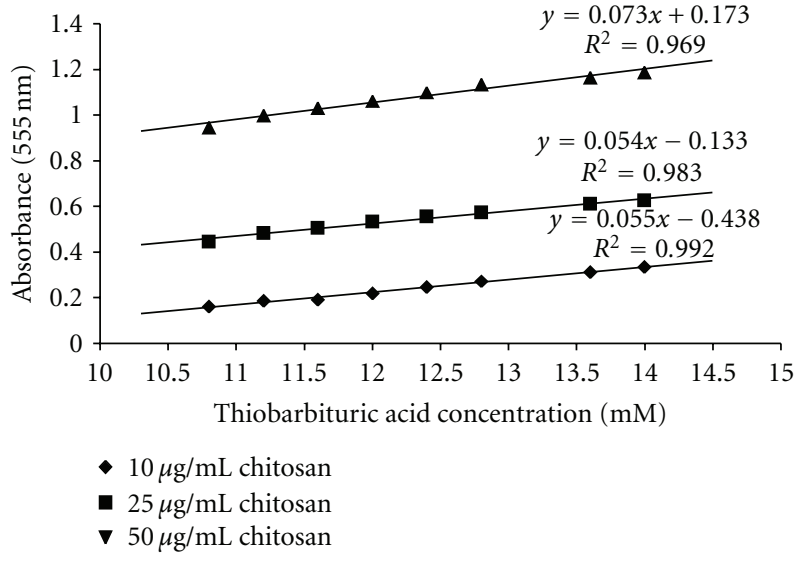

(b)

FIGURE 4: Influence of the concentration of thiobarbituric acid on the intensity of the color development (a) and the linear correlation between thiobarbituric acid and color development (b).

$\mathrm{NaNO}_{2}$ but also by the initial concentration of chitosan. This phenomenon is related to the structure of chitosan in the solution. Normally chitosan molecule takes the shape of an extended random coil in the solution. When the concentration is high, due to the larger viscosity of the solution and strong intermolecular interactions, accessible chain segments can only stretch in a limited area, decreasing the contact probability with $\mathrm{NaNO}_{2}$, thus resulting in a lower degradation rate. In this case, low chitosan concentration would be preferred to yield end product in a short time.

\subsubsection{Effect of the TBA Concentration on Development of the} Color. In order to study the effect of thiobarbituric acid, three chitosan concentrations $(10,25$, and $50 \mathrm{ug} / \mathrm{mL})$ were tested then the absorbencies at $555 \mathrm{~nm}$ were then plotted against serial concentrations of the thiobarbituric acid (Figure 4(a)). The influence of the thiobarbituric acid concentration was studied in the range between 1 to $14 \mathrm{mM}$. The rate of the reaction was found to increase continuously (presumably as reducing ends are produced) with a concentration of the thiobarbituric acid reagent up to $10 \mathrm{mM}$ and then remain constant between 11.2 to $14 \mathrm{mM}$. A concentration of $10.8 \mathrm{mM}$ of thiobarbituric acid was selected as the optimum concentration for the three chitosan concentrations. Moreover, regression analysis of the thiobarbituric acid concentrations ranged from 10.8 to $14 \mathrm{mM}$ yielded a linear correlation with correlation coefficients of $0.992,0.983$, and 0.969 for 10,25 , and $50 \mu \mathrm{g} / \mathrm{mL}$ chitosan, respectively (Figure 4(b)).

3.2.3. Effect of the Reaction Time on the Color Development. In order to investigate the effect of the reaction time, keeping $\mathrm{NaNO}_{2}$ and thiobarbituric acid at 25 and $10.8 \mathrm{mM}$, respectively, chitosan concentrations from 5 to $100 \mu \mathrm{g} / \mathrm{mL}$ were degraded by $\mathrm{NaNO}_{2}$ in $1 \%$ acetic acid solution (v/v) and the reaction was examined after 15,30 , and $45 \mathrm{~min}$, and the corresponding samples were processed in the same way as that described before. The absorbance values of the samples were determined at $555 \mathrm{~nm}$, and the results are illustrated in Figure 5(a). It will be observed from the readings given in this figure that the maximum color intensity developed after the solutions have been heated for $30 \mathrm{~min}$. This means that complete depolymerization or total acid hydrolysis of all chitosan concentrations occurred mainly in the first $30 \mathrm{~min}$. It has been found that the colors obtained after heating of the chitosan solutions with $\mathrm{NaNO}_{2}$ reagent for $45 \mathrm{~min}$ or longer are of a slightly different tint from those obtained with solutions which have been heated for $30 \mathrm{~min}$. Therefore, this time was selected as the optimum for the determination reaction.

3.2.4. Effect of the $p H$. Another possible reason for the low color yields could be differences in the $\mathrm{pH}$ optimum for the reaction. The thiobarbituric acid reaction was carried out in the $\mathrm{pH}$ that ranged from 5 to 12 (Figure $5(\mathrm{~b})$ ). The pink complex gave its maximal absorbance only within a narrow $\mathrm{pH}$ interval, 7-8. The three chitosan concentrations gave highest color yield at $\mathrm{pH} \approx 8$. Therefore, this $\mathrm{pH}$ value was selected as the optimum for the determination reaction.

3.2.5. Calibration Curve and Final Optimized Assay. Different concentrations of chitosan ranged from 5 to $60 \mu \mathrm{g} / \mathrm{mL}$ were mixed in test tubes with $100 \mu \mathrm{L}$ of $\mathrm{NaNO}_{2}(0.5 \mathrm{M})$. After incubating for $30 \mathrm{~min}$ at $80^{\circ} \mathrm{C}$ in a static water bath, the $\mathrm{pH}$ was increased to 8 by adding $200 \mu \mathrm{L} \mathrm{NaOH}(0.1 \mathrm{M}) .540 \mu \mathrm{L}$ of thiobarbituric acid $(0.04 \mathrm{M})$ was added, and the tubes were incubated a second time at $80^{\circ} \mathrm{C}$ for $10 \mathrm{~min}$ in a water bath and then cooled to room temperature. The absorbance was measured at $555 \mathrm{~nm}$ by spectrophotometer. The plot of absorbencies against serial concentrations of chitosan gave straight line as shown in Figure 6.

3.2.6. Stability of the Color Complex. The color of complex formed (Table 1) remained stable between 5 and $180 \mathrm{~min}$ after color development. Fading of the color with time was found to be very slow, and no fading occurred during the 


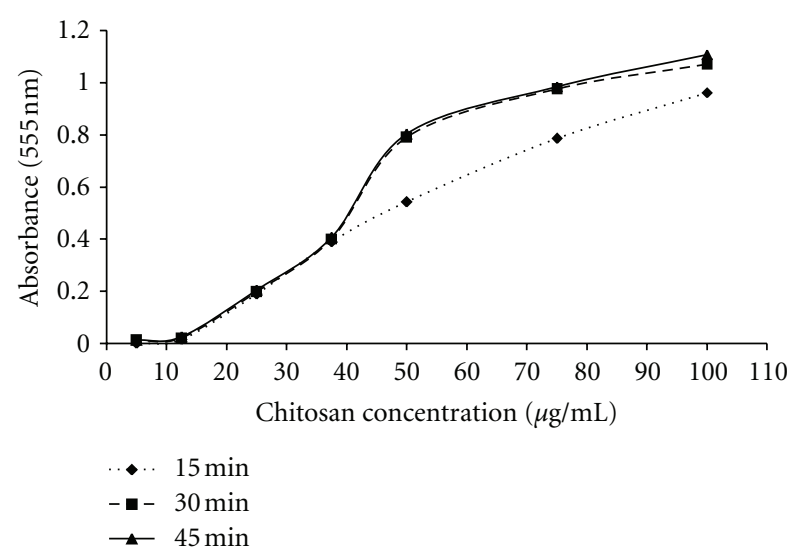

(a)

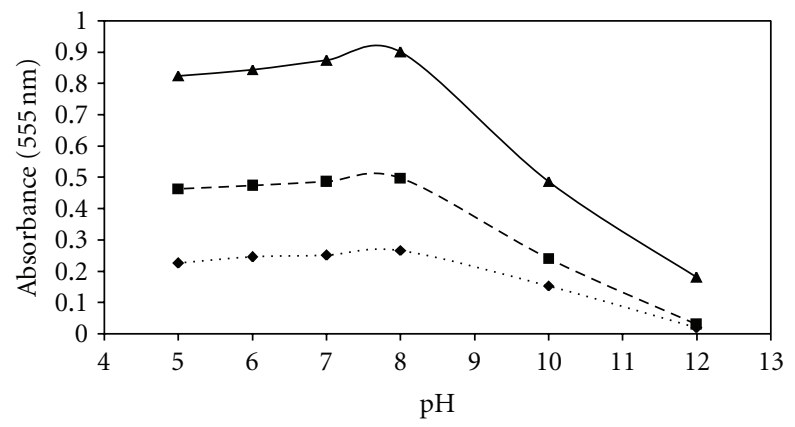

- $10 \mu \mathrm{g} / \mathrm{mL}$ chitosan

- - $25 \mu \mathrm{g} / \mathrm{mL}$ chitosan

$\rightarrow 50 \mu \mathrm{g} / \mathrm{mL}$ chitosan

(b)

Figure 5: The influence of the time of heating with the sodium nitrite reagent on the subsequent color development (a) and the function of $\mathrm{pH}$ for reaction of the reducing end of chitosan with thiobarbituric acid after 30 min reaction time (b).

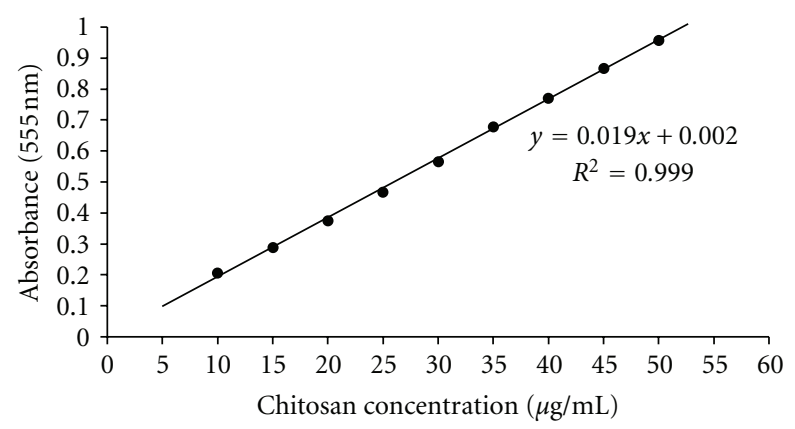

Figure 6: Standard analytical curve for chitosan at optimum conditions in the proposed method at $555 \mathrm{~nm}$. Each value is the mean of four determinations.

first $180 \mathrm{~min}$, even when exposed to indoors illumination as long as direct sunlight was avoided. After $12 \mathrm{~h}$, decrease in absorbance was recorded, not exceeding $1 \%$ per hour.

3.3. Analytical Sensitivity. As for the slope of the calibration line, analytical sensitivity for chitosan determination was
TABLE 1: Stability of color complex by the proposed method.

\begin{tabular}{|c|c|c|c|}
\hline \multirow[t]{2}{*}{ Time after color development ( $\mathrm{min}$ ) } & \multicolumn{3}{|c|}{$\begin{array}{l}\text { Absorbance }(555 \mathrm{~nm}) \text { with } \\
\text { the following amount of } \\
\text { chitosan }(\mu \mathrm{g} / \mathrm{mL})\end{array}$} \\
\hline & 5 & 10 & 25 \\
\hline 5 & 0.086 & 0.151 & 0.410 \\
\hline 10 & 0.086 & 0.152 & 0.412 \\
\hline 15 & 0.091 & 0.153 & 0.415 \\
\hline 20 & 0.095 & 0.154 & 0.411 \\
\hline 25 & 0.098 & 0.152 & 0.410 \\
\hline 30 & 0.098 & 0.152 & 0.411 \\
\hline 35 & 0.101 & 0.154 & 0.412 \\
\hline 40 & 0.100 & 0.152 & 0.411 \\
\hline 45 & 0.100 & 0.154 & 0.409 \\
\hline 50 & 0.102 & 0.157 & 0.409 \\
\hline 55 & 0.097 & 0.155 & 0.404 \\
\hline 60 & 0.100 & 0.157 & 0.405 \\
\hline 90 & 0.092 & 0.153 & 0.402 \\
\hline 120 & 0.092 & 0.153 & 0.409 \\
\hline 150 & 0.092 & 0.150 & 0.407 \\
\hline 180 & 0.092 & 0.150 & 0.414 \\
\hline $1080(18 \mathrm{~h})$ & 0.046 & 0.080 & 0.231 \\
\hline
\end{tabular}

The values are means of four replicates.

found to be 0.0019 absorbance/amount $(0.1 \mu \mathrm{g} / \mathrm{mL}$ chitosan).

3.4. Linearity of the Color Responses. A linear relationship between the absorbance and the chitosan quantity was observed within the range of $10-50 \mu \mathrm{g} / \mathrm{mL}$. The upper limit of the linearity in the assay was $50 \mu \mathrm{g} / \mathrm{mL}$ chitosan. In the regression analysis, the $r$ value was $0.999, P<0.001$, the slope was 0.0191 , and the intercept was 0.0028 .

3.5. Lower Detection Limit. The detection limit of the method was determined by evaluating the zero calibrator 10 times. The limit of detection (LoD), defined as the mean chitosan value of the zero calibrator (limit of blank, LoB) +1.645 (SD low concentration sample) according to the method of Armbruster and Pry [29], was found to be 0.185 , where LoB $=$ mean blank +1.645 (SD blank).

3.6. Applications. To evaluate the performance of the method for analysis of real samples, determination of chitosan in pharmaceutical formulation of Chitocal capsules was investigated. The results presented in Table 2 revealed that the capsules product presented contents of chitosan in the range of 73.82 to $80.81 \%$ of that reported on the label with average of $76.11 \%$. In addition, the recoveries for the addition of different concentrations of chitosan to Chitocal samples are in the range of 96.67 to $98.46 \%$ with average of $97.68 \%$ and indicate that the proposed method is suitable for determination of trace amounts of chitosan in the real samples. 
TABLE 2: Determination of chitosan in pharmaceutical formulation by the proposed method.

\begin{tabular}{lcccccc}
\hline Sample & $\begin{array}{c}\text { Chitosan content } \\
\text { declared in label }(\mathrm{mg})\end{array}$ & $\begin{array}{c}\text { Sample taken } \\
(\mu \mathrm{L})\end{array}$ & $\begin{array}{c}\text { Chitosan } \\
\text { calculated }(\mathrm{mg})\end{array}$ & $\begin{array}{c}\text { Chitosan found } \\
(\mathrm{mg})\end{array}$ & $\begin{array}{c}\text { \% of chitosan in } \\
\text { formulation } \pm \mathrm{SE}\end{array}$ & Recovery $(\%)^{\mathrm{a}} \pm \mathrm{SE}$ \\
\hline & & 20 & 0.029 & 0.022 & $73.82 \pm 1.54$ & $96.67 \pm 1.75$ \\
& & 40 & 0.059 & 0.044 & $74.86 \pm 1.87$ & $97.28 \pm 0.88$ \\
Chitocal capsule & $500 \mathrm{mg}$ & 60 & 0.088 & 0.067 & $75.52 \pm 1.84$ & $97.89 \pm 0.56$ \\
& & 80 & 0.118 & 0.089 & $75.59 \pm 2.19$ & $98.11 \pm 1.15$ \\
& & 100 & 0.147 & 0.119 & $80.81 \pm 2.51$ & $98.46 \pm 0.82$ \\
Mean \pm SE & & & & $76.11 \pm 1.55$ & $97.68 \pm 0.32$ \\
\hline
\end{tabular}

${ }^{a}$ Recovery (\%) values were calculated from the amount of chitosan that had been determined after addition of its different amounts to a fixed amount of dosage form (capsule). The data are average of three determintaions.

In spite of the availability of several methods for quantitative determination of chitosan, only isolated examples have been found on the estimation of the content of this polymer in different samples. In the present study, a method for quantifying the chitosan in pure and commercial products was developed. This method is based on the previous reports on its unique degradability in nitrous acid solution. In previous reports, hydrochloric acid was used for the hydrolysis of chitin and chitosan prior to glucosamine analysis $[19,30-33]$. However, hydrolysis by $\mathrm{HCl}$ is usually a timeconsuming process to achieve complete depolymerization and high yield. Bosworth and Scott [19] reported that the maximum yield of hydrolysis of chitosan with $5.5 \mathrm{~N} \mathrm{HCl}$ at $102^{\circ} \mathrm{C}$ was not reached in less than $23 \mathrm{~h}$. Chen and Chiou [30] recovered only $63.7 \%$ of chitin as glucosamine after $60 \mathrm{~min}$ of hydrolysis with $2.5 \mathrm{M} \mathrm{HCl}$ at $140^{\circ} \mathrm{C}$. Wu et al. [34] used $6 \mathrm{M} \mathrm{HCl}$ at $110^{\circ} \mathrm{C}$ and recovered $93.0 \%$ of chitosan after $3 \mathrm{~h}$ and only $68.7 \%$ of chitin after $12 \mathrm{~h}$ as glucosamine. Zhu et al. [33] got $85.3 \%$ recovery of chitin at $110^{\circ} \mathrm{C}$ after $4 \mathrm{~h}$. In all of these works, the sum of free and acetylated glucosamine was reported. The recoveries of chitosan from the commercial preparation with the present method were $>98 \%$ (Table 2), indicating high performance of the method for the analysis of materials containing this biopolymer.

In earlier methods, glucosamine has been quantified by hydrolysis in $\mathrm{HCl}$ solutions. However, part of the sample that was not depolymerized by $\mathrm{HCl}$ and stayed in the solid form was not included in the measurement $[19,30,33,34]$. However, in the present method, chitosan samples dissolved in aqueous acetic acid solution and became completely soluble and the chitosan is not precipitated from the solution. In this case, the whole initial sample is considered for the estimation of chitosan content.

\section{Conclusions}

A colorimetric method is described for the determination of chitosan in pure and pharmaceutical formulation. This method depends on the acid hydrolysis of chitosan molecule by one step with sodium nitrite treatment to convert it into 2,5-anhydro-D-mannose at the new reducing end which reacts with thiobarbituric acid in basic medium to give rise very stable pink-colored solution. The procedure has been applied for estimation of the chitosan in Chitocal capsules as a pharmaceutical formulation with high recoveries of 96.67 to $98.46 \%$, indicating that the proposed method is suitable for determination of trace amounts of chitosan in the real samples.

\section{References}

[1] H. K. No and S. P. Meyers, "Preparation of chitin and chitosan," in Chitin Handbook, R. A. A. Muzzarelli and M. G. Peter, Eds., pp. 475-489, European Chitin Society, 1997.

[2] S. Hirano, "Chitin biotechnology applications," Biotechnology Annual Review, vol. 2, pp. 237-258, 1996.

[3] Y. Shigemasa and S. Minami, "Applications of chitin and chitosan for biomaterials," Biotechnology and Genetic Engineering Reviews, vol. 13, pp. 383-420, 1996.

[4] E. I. Rabea, M. E. T. Badawy, C. V. Stevens, G. Smagghe, and W. Steurbaut, "Chitosan as antimicrobial agent: applications and mode of action," Biomacromolecules, vol. 4, no. 6, pp. 14571465, 2003.

[5] F. Shahidi, J. K. V. Arachchi, and Y. J. Jeon, "Food applications of chitin and chitosans," Trends in Food Science and Technology, vol. 10, no. 2, pp. 37-51, 1999.

[6] M. Eikenes, M. Fongen, L. Roed, and Y. Stenstrøm, "Determination of chitosan in wood and water samples by acidic hydrolysis and liquid chromatography with online fluorescence derivatization," Carbohydrate Polymers, vol. 61, no. 1, pp. 29-38, 2005.

[7] A. Tsuji, T. Kinoshita, and M. Hoshino, "Analytical chemical studies on amino sugars. II. Determination of hexosamines using 3-methyl-2-benzothiazolone hydrazone hydrochloride," Chemical and Pharmaceutical Bulletin, vol. 17, no. 7, pp. 15051510, 1969.

[8] A. Tsuji, T. Kinoshita, and M. Hoshino, "Microdetermination of hexosamines," Chemical and Pharmaceutical Bulletin, vol. 17, no. 1, pp. 217-218, 1969.

[9] S. Roseman and I. Daffner, "Colorimetric method for determination of glucosamine and galactosamine," Analytical Chemistry, vol. 28, no. 11, pp. 1743-1746, 1956.

[10] N. I. Larionova, D. K. Zubaerova, D. T. Guranda, M. A. Pechyonkin, and N. G. Balabushevich, "Colorimetric assay of chitosan in presence of proteins and polyelectrolytes by using o-phthalaldehyde," Carbohydrate Polymers, vol. 75, no. 4, pp. 724-727, 2009.

[11] Z. Dische and E. Borenfreund, "A spectrophotometric method for the microdetermination of hexosamines," The Journal of Biological Chemistry, vol. 184, no. 2, pp. 517-522, 1950. 
[12] E. Curotto and F. Aros, "Quantitative determination of chitosan and the percentage of free amino groups," Analytical Biochemistry, vol. 211, no. 2, pp. 240-241, 1993.

[13] S. Prochazkova, K. M. Vårum, and K. Østgaard, "Quantitative determination of chitosans by ninhydrin," Carbohydrate Polymers, vol. 38, no. 2, pp. 115-122, 1999.

[14] C. Wischke and H. H. Borchert, "Increased sensitivity of chitosan determination by a dye binding method," Carbohydrate Research, vol. 341, no. 18, pp. 2978-2979, 2006.

[15] B. Miralles, M. Mengíbar, R. Harris, and A. Heras, "Suitability of a colorimetric method for the selective determination of chitosan in dietary supplements," Food Chemistry, vol. 126, no. 4, pp. 1836-1839, 2011.

[16] R. A. A. Muzzarelli, "Colorimetric determination of chitosan," Analytical Biochemistry, vol. 260, no. 2, pp. 255-257, 1998.

[17] D. Sekmokiene, V. Speiciene, A. Salaseviciene, and G. Garmiene, "Determination of chitosan in food products," Veterinarija ir Zootechnika, vol. 31, pp. 87-92, 2005.

[18] G. Lu, L. Wang, R. Wang, Y. Zeng, and X. Huang, "Determination of chitosan by cathodic stripping voltammetry," Analytical Sciences, vol. 22, no. 4, pp. 575-578, 2006.

[19] T. R. Bosworth and J. E. Scott, "A specific fluorometric assay for hexosamines in glycosaminoglycans, based on deaminative cleavage with nitrous acid," Analytical Biochemistry, vol. 223, no. 2, pp. 266-273, 1994.

[20] A. Zamani, A. Jeihanipour, L. Edebo, C. Nlklasson, and M. J. Taherzadeh, "Determination of glucosamine and $N$-acetyl glucosamine in fungal cell walls," Journal of Agricultural and Food Chemistry, vol. 56, no. 18, pp. 8314-8318, 2008.

[21] L. Daniels, R. S. Hanson, and J. A. Phillips, "Chemical analysis," in Methods for General and Molecular Bacteriology, P. Gerhardt, R. G. E. Murray, W. A. Wood, and N. R. Krieg, Eds., pp. 518-519, American Society for Microbiology, Washington, DC, USA, 1994.

[22] M. Izume and A. Ohtakara, "Preparation of D-glucosamine oligosaccharides by the enzymatic hydrolysis of chitosan," Agricultural and Biological Chemistry, vol. 51, pp. 1989-11991, 1987.

[23] S. Mao, X. Shuai, F. Unger, M. Simon, D. Bi, and T. Kissel, "The depolymerization of chitosan: effects on physicochemical and biological properties," International Journal of Pharmaceutics, vol. 281, no. 1-2, pp. 45-54, 2004.

[24] H. Sashiwa, H. Saimoto, Y. Shigemasa, and S. Tokura, "Nacetyl group distribution in partially deacetylated chitins prepared under homogeneous conditions," Carbohydrate Research, vol. 242, pp. 167-172, 1993.

[25] G. G. Allan and M. Peyron, "Molecular weight manipulation of chitosan. I: kinetics of depolymerization by nitrous acid," Carbohydrate Research, vol. 277, no. 2, pp. 257-272, 1995.

[26] G. G. Allan and M. Peyron, "Molecular weight manipulation of chitosan. II: prediction and control of extent of depolymerization by nitrous acid," Carbohydrate Research, vol. 277, no. 2, pp. 273-282, 1995.

[27] K. Tømmeraas, K. M. Vårum, B. E. Christensen, and O. Smidsrød, "Preparation and characterisation of oligosaccharides produced by nitrous acid depolymerisation of chitosans," Carbohydrate Research, vol. 333, no. 2, pp. 137-144, 2001.

[28] L. F. Tietze and U. Beifuss, "Sequential transformations in organic chemistry: a synthetic strategy with a future," Angewandte Chemie International Edition in English, vol. 32, no. 2, pp. 131-163, 1993.

[29] D. A. Armbruster and T. Pry, "Limit of blank, limit of detection and limit of quantitation," Clinical Biochemistry Review, vol. 29, supplement i, pp. S49-S52, 2008.
[30] W. Chen and R. Y. Y. Chiou, "A modified chemical procedure for rapid determination of glucosamine and its application for estimation of mold growth in peanut kernels and koji," Journal of Agricultural and Food Chemistry, vol. 47, no. 5, pp. 19992004, 1999.

[31] C. H. Ng, S. Hein, S. Chandrkrachang, and W. F. Stevens, "Evaluation of an improved acid hydrolysis-HPLC assay for the acetyl content in chitin and chitosan," Journal of Biomedical Materials Research-Part B, vol. 76, no. 1, pp. 155$160,2006$.

[32] F. Niola, N. Basora, E. Chornet, and P. F. Vidal, "A rapid method for the determination of the degree of $\mathrm{N}$-acetylation of chitin-chitosan samples by acid hydrolysis and HPLC," Carbohydrate Research, vol. 238, pp. 1-9, 1993.

[33] X. Zhu, J. Cai, J. Yang, and Q. Su, "Determination of glucosamine in impure chitin samples by high-performance liquid chromatography," Carbohydrate Research, vol. 340, no. 10, pp. 1732-1738, 2005.

[34] T. Wu, S. Zivanovic, F. A. Draughon, and C. E. Sams, "Chitin and chitosan-value-added products from mushroom waste," Journal of Agricultural and Food Chemistry, vol. 52, no. 26, pp. 7905-7910, 2004. 


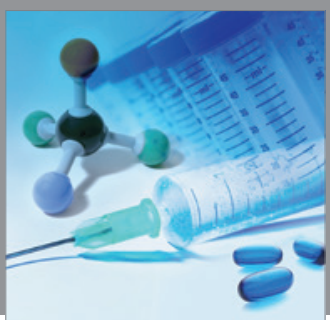

International Journal of

Medicinal Chemistry

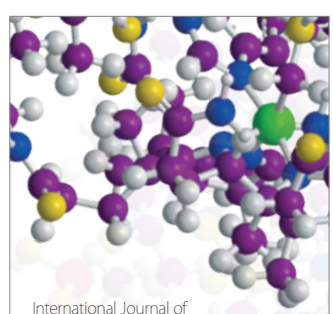

Carbohydrate Chemistry

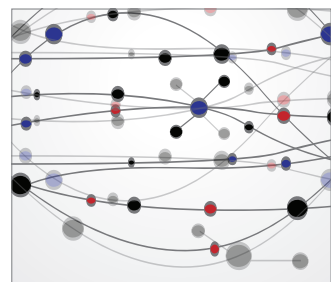

The Scientific World Journal
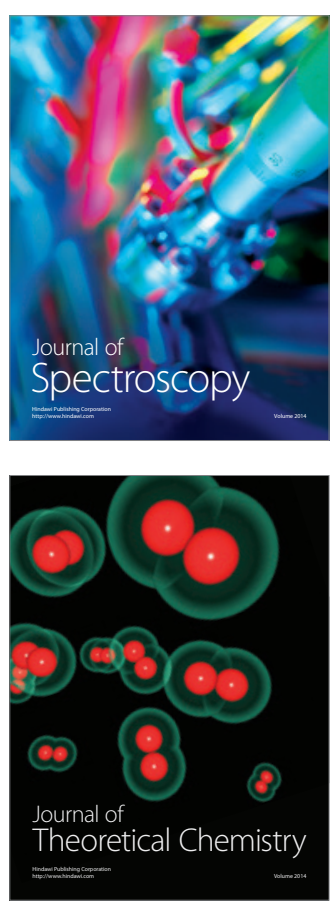
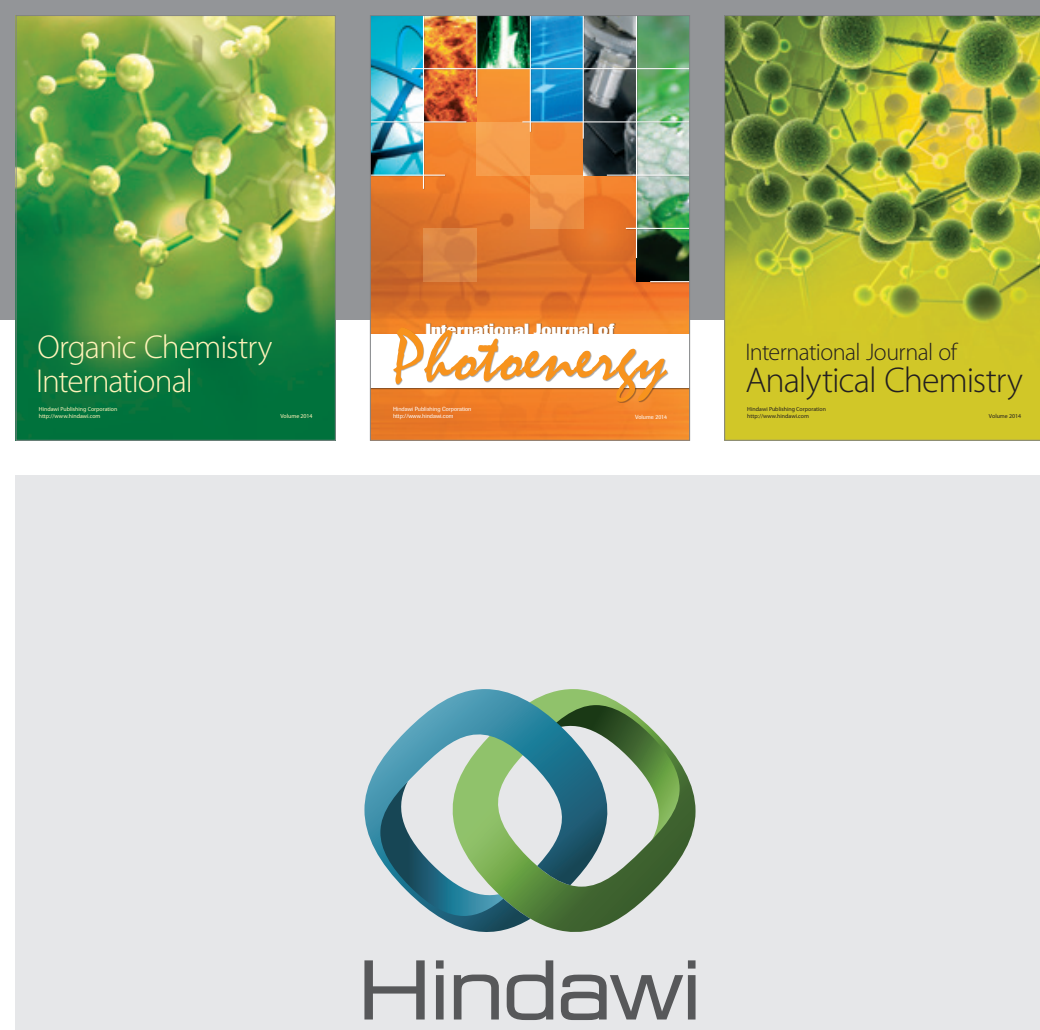

Submit your manuscripts at

http://www.hindawi.com
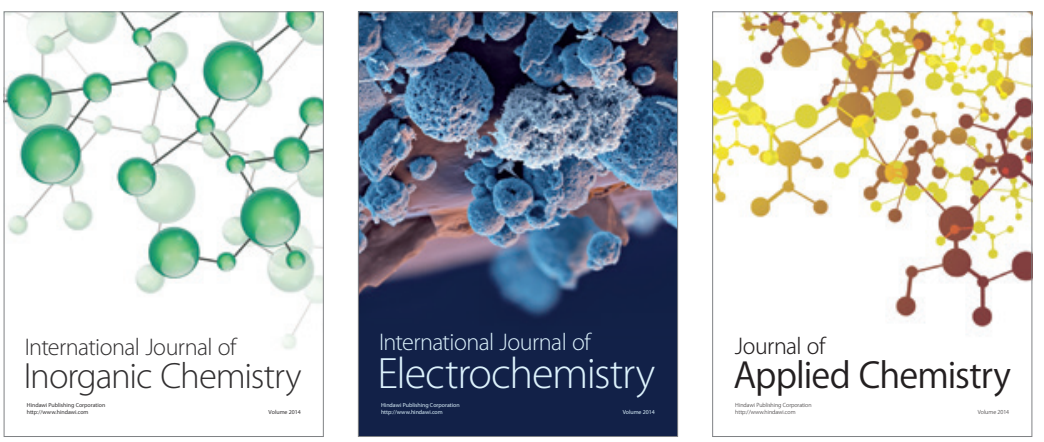

Journal of

Applied Chemistry
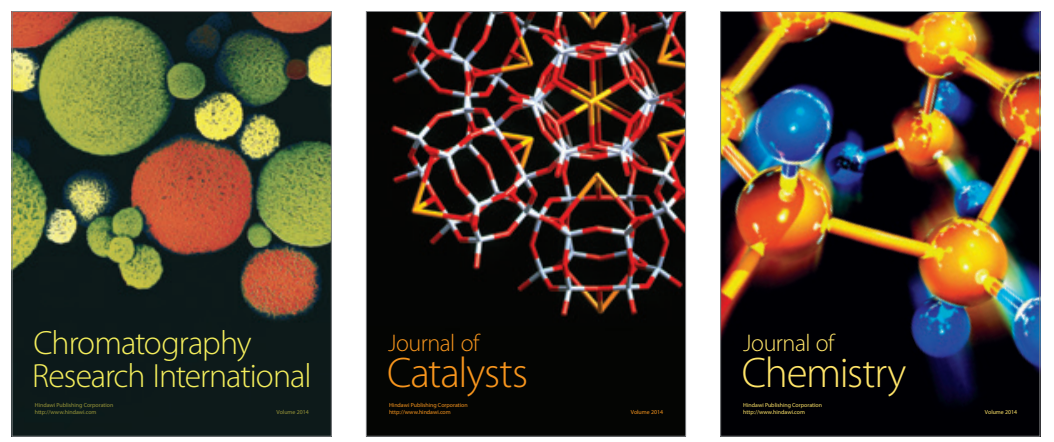
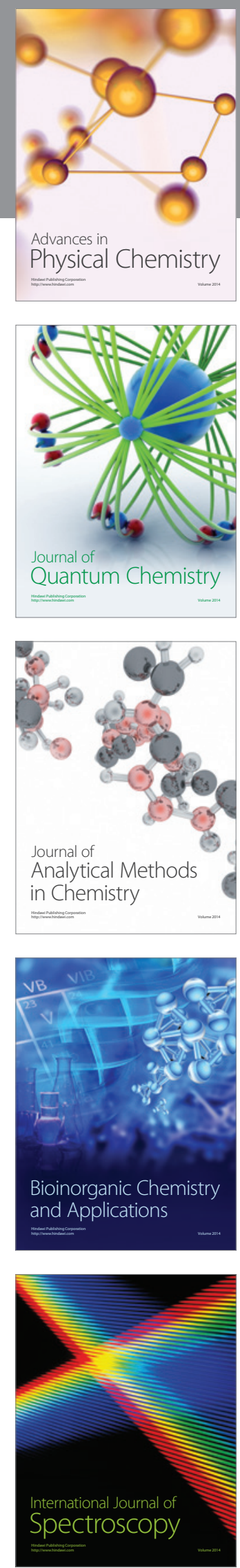